\title{
Hyperbilirubinemia and Transcutaneous Bilirubin Estimation - An Update
}

\author{
Dr. Vaneet Kaur ${ }^{1}$, Dr. Brinder Chopra ${ }^{2}$, Dr. Amandeep Kaur ${ }^{3}$, \\ Dr. Minni Verma ${ }^{4}$, Dr. Kamaljit Singh ${ }^{5}$ \\ ${ }^{1,2,3}$ (Associate Professor,Department of Biochemistry, Gian Sagar Medical College, Ramnagar, Patiala, India) \\ ${ }^{4,5}$ (Professor ,Department of Biochemistry, Gian Sagar Medical College, Ramnagar, Patiala, India)
}

\section{Introduction}

The term hyperbilirubinemia describes an excess of bilirubin in the blood. This becomes clinically apparent as jaundice, a yellow colouration of the skin and whites of the eyes, which occurs in newborns at serum bilirubin levels $>5 \mathrm{mg} / \mathrm{dL}$. Neonatal hyperbilirubinemia (jaundice) occurs in more than $60 \%$ of late preterm and term newborns, peaking at 3-5 days of life and usually resolving by 2 weeks of age( 1 ). While hyperbilirubinemia (total serum bilirubin $>1.0 \mathrm{mg} / \mathrm{dl}$ ) occurs in nearly all infants, significant hyperbilirubinemia(TSB $>12.9 \mathrm{mg} / \mathrm{dL}$ ) and excessive hyperbilirubinemia(TSB values above the 95 th percentile for age in hours) occurs in only $5 \%$ to $6 \%$ of the healthy newborn population(2-6). Severe jaundice ( Hyperbilirubinemia) can result in kernicterus(Bilirubin Encephalopathy) causing irreversible brain damage to the patient. Risk factors recognized to be associated with severe hyperbilirubinemia in newborns include jaundice in the first 24 hours of life, jaundice noted before discharge from hospital, a sibling who had jaundice treated with phototherapy, near-term gestational age of 35-36 weeks, Asian race and the presence of infant bruising or cephalhaematoma (7-9). Estimates in developed countries range from about 0.4 to 2 per 100000 (1016). Infants who are sick or preterm, are at risk of developing kernicterus at lower TSB concentrations compared to the term neonate $(\underline{17})$.

The gold standard to assess jaundice in neonates is total serum bilirubin measurement(18). Transcutaneous measurements of bilirubin have a linear correlation to total serum bilirubin and may be useful as screening devices to detect clinically significant jaundice and decrease the need for serum bilirubin determinations(19).

Presently the standard treatment for hyperbilirubinemia is phototherapy which is generally effective but in some cases, when the plasma bilirubin concentrations become dangerously high or rise rapidly despite phototherapy, exchange transfusion is indicated which has more serious side-effects and complications than phototherapy. The mortality rate from the procedure is approximately $0.3-2 \%$ and significant morbidity is associated with $5-12 \%$ of exchange transfusions(20-22).

Phototherapy with light of wavelength in the 430 to $490 \mathrm{~nm}$ spectrum is much safer than exchange transfusion, although it is expensive and leads to separation of mother and infant(23-26).

\section{Recommended guidelines for hyperbilirubinemia}

Although jaundice in newborns can be usually detected by blanching the skin with digital pressure and is usually visible in the face with caudal progression, visual estimation of bilirubin levels is largely inaccurate and unreliable(27). Dark pigmentation adds an additional degree of difficulty in visual estimation in some studies(28-29).

Both the American Academy of Paediatrics (AAP )(30) and the Canadian Paediatric Society (CPS [31]) have published guidelines regarding the management of neonatal hyperbilirubinemia in term infants. American Academy of Paediatrics (AAP) recommends that every newborn be assessed for the risk of developing severe hyperbilirubinemia, by using predischarge Total Serum Bilirubin (TSB) or Transcutaneous Bilirubin measurements and assessment of clinical risk factors before discharge(30). The AAP also considers the use of transcutaneous bilirubin (TcB) level as an alternative to TSB measurement, and the results of studies $(19,30)$ have confirmed the value of transcutaneous bilirubinometry. The American Academy of Paediatrics( AAP) also recommends the use of an hour specific nomogram to aid the decision making process regarding neonatal jaundice for full term and late pre-term neonates(30). The AAP also recommends consideration of risk factors that are significantly associated with hyperbilirubinemia. The guidelines for hyperbilirubinemia do not differ among neonates with varying risk factors, rather, they state that the risk of severe hyperbilirubinemia is extremely low if no risk factors are present and the risk of severe hyperbilirubinemia increases with more risk factors $(30,32)$. 
In 2007 , the Canadian Paediatric Society for the detection, management, and prevention of hyperbilirubinemia in term and late preterm newborn infants recommended that TSB or TcB be measured in all infants during the first 72 hours of life with individualized follow-up based on risk assessment(31).

It has also been shown by Eggert et al (33) that, after the initation of Universal Bilirubin Screening Program, the incidence of TSB levels of $\geq 25 \mathrm{mg} / \mathrm{dL}$ decreased from 1 in 1522 infants to 1 in 4037 infants.

\section{Transcutaneous bilirubin}

Transcutaneous bilirubinometry is a safe and effective technique in well-term and near-term newborns $(34,35)$. It is based on the principle that the instruments which measure transcutaneous bilirubin concentration operate by transmitting light that penetrates the blanched skin and transilluminates the subcutaneous tissues. The scattered light returns through a fibre optic filament and the yellowness of the reflected light- corrected for the contribution of haemoglobin, melanin and dermal thickness is measured in a spectrophotometric module and converted into an estimate of TSB concentration(36). Transcutaneous bilirubinometers measure the yellowness of the skin and subcutaneous tissue and the contribution of serum Bilirubin to this measurement is minimal(37).Thus, a TcB measurement is not equivalent of measuring TSB.

\section{Instruments for measuring transcutaneous bilirubin}

The most important feature of a screening tool for neonatal jaundice is its capability to detect significant hyperbilirubinemia with $100 \%$ sensitivity(18) and the device must also have a desirable level of specificity because over-diagnosis leads to unnecessary admissions and work. The first transcutaneous bilirubinometer was introduced in 1980. Many transcutaneous bilirubinometers for measuring TcB have been described in the literature like (the Minolta Air- Shields jaundice meter, Ingram Icterometer, Bilicheck, and Chromatics ColorMate III). All of them have a linear correlation to TSB and may be useful as screening devices to detect clinically significant jaundice and decrease the need for serum bilirubin determinations. But the recently introduced Bilicheck device, which uses reflectance data from multiple wavelengths, seems to be a significant improvement over the older devices (the Ingram Icterometer and the Minolta Air-Sheilds jaundice meter) because of its ability to determine correction factors for the effect of melanin and haemoglobin(19).A number of studies have been conducted to study about the correlation of TcB on Bilicheck with TSB. Hammati et al (18) studied about the value of Bilicheck (R) as a screening tool for neonatal jaundice in south of Iran and observed a good correlation between TcB and TSB $(r=0.969)$ which was not affected by sex, gestational age ,perinatal age and birth weight thus proving Bilicheck as a noninvasive, simple, easy and reliable method for bilirubin measurement in neonatal jaundice, especially in neonates with bilirubin levels $\leq 15 \mathrm{mg} \%$. Also, the maximum sensitivity, specificity, and especially NPV were at the TSB cut-off value of $15 \mathrm{mg} / \mathrm{dl}$, thus indicating a tendency to underestimate TSB levels in infants with higher bilirubin levels. The Biicheck ${ }^{\circledR}$ is, therefore, a reliable screening tool for hyperbilirubinemia with bilirubin levels $\leq 15 \mathrm{mg} / \mathrm{dl}$; this finding chimes in with those of the Samanta S et al(38) and Ho EY et al(39). On the other hand, JM-103, Konica Minolta, Osaka, Japan is a non-invasive medical device that is easy to use at bedside, delivers prompt measurements, and is minimally influenced by skin pigmentation .Yasuda et al(40) found an excellent correlation( $\mathrm{r}=0.93)$ between $\mathrm{TcB}$ (measured by JM-103) and TSB among Japanese term neonates. Another transcutaneous meter Bilimed evaluated by De Luca et al (41) found it to be less accurate than Bilichek and not recommended for current clinical practice.. Raimondi et al conducted a comparative analysis of the most widespread transcutaneous bilirubinometers on a multiracial population of term and late pre-term neonates and concluded that Bilicheck and JM-103, but not Bilimed, are equally reliable screening tools for hyperbilirubenemia(42). But a clean, disposable tip is required for each measurement while using Bilicheck, substantially increasing the cost of the test(19). According to National Academy of Clinical Biochemistry laboratory medicine practice guidelines, only Bilicheck and JM-103 have been recommended for use in in clinical setting as they provide results comparable to laboratory $\operatorname{TSB}(43,44)$.

\section{Site of transcutaneous bilirubin estimation}

The selection of TcB measurement site depends upon the goal of TcB measurement. The forehead is the most frequent site of TcB measurement as mentioned in research studies. Randeberg et al (45) found that $\mathrm{TcB}$ measurements on neonates taken from the heel, back, or thigh did not correlate as well with TSB as those taken from the forehead. Maisels et al (46), however, found better correlation with TSB when TcB measurements were performed on the sternum $(\mathrm{r}=0.953)$ compared with the forehead $(\mathrm{r}=0.914)$. A similar study was conducted by Poland et al (47) which also revealed that chest readings showed a better correlation with serum values as compared to brow. In addition, it was suggested that measurements from the sternum, which is less likely to be exposed to sunlight or ambient light, may be more desirable, especially when measurements are taken after infants have been discharged from hospital(48). Another site was explored for measuring transcutaneous bilirubin by Yaser et al(49) who found that interscapular site is superior and safer for 
screening preterm neonates as compared to forehead and sternum as it had the highest sensitivity of $94 \%$ and lowest false negative rate of $6 \%$.

\section{Impact on Length of stay and Readmission Rate}

Hyperbilirubinemia is emerging as an increasingly common problem in newborns due to a decreasing hospital length stay after birth(50). In a retrospective study, Peterson et al(51) reviewed 6603 newborns over a time period of 8 months before and after implementation of TcB measurements. These investigators found that availability of $\mathrm{TcB}$ measurements was not associated with a decrease in the mean length of stay for normal newborns, the number of newborns with hyperbilirubinemia requiring phototherapy before discharge, or the number of days of treatment with phototherapy. However, they did note a significant reduction in the number of hospital readmissions per 1000 newborns for clinically significant hyperbilirubinemia, from a mean (SD) of 4.5 (2.4) to $1.8(1.7)$, and a statistically significant increase in the monthly incidence of phototherapy treatment before discharge from $5.9 \%(1.3 \%)$ to $7.7 \%(1.3 \%)$ after implementation of $\mathrm{TcB}$ measurements. They speculated that the convenience and rapid turnaround time of TcB testing may have encouraged more effective screening and identification of newborns with clinically significant hyperbilirubinemia before discharge. Also, it may reduce the need for serum Bilirubin measurements(52-54) and subsequent readmission for phototherapy $(51)$.

\section{Accuracy of Transcutaneous Bilirubin vs Total serum Bilirubin}

Total Serum Bilirubin ( TSB) levels are measured by invasive blood sampling which is painful and stressful for the neonate. It results in blood loss and predisposes the infant to increased risk for osteomyelitis and infections at the site of sampling $(55,56)$. It can also cause anaemia and increase the risk of scar formation(57). In addition the method is laborious and time consuming, lacking the possibility for immediate diagnosis. Also, it has been seen that TSB is not necessary in every jaundiced infant. For example, in low risk infants 4 or more days old, phototherapy is not recommended by the AAP unless the TSB is $20 \mathrm{mg} / \mathrm{dl}$ or more. TcB provides many advantages over TSB including instantaneous measurements without requiring a painful lab draw. For infants $>35$ weeks, TcB can reliably identify infants at risk for severe hyperbilirubinemia and can decrease the number of TSB measurements obtained(58).

As regards the methods available for measuring total serum bilirubin, HPLC is generally taken as the gold standard, although this method is not widely used in clinical practice .Other methods in use for estimation of total serum bilirubin are diazo based methods(59) that have interferences with hemoglobin and other intracellular compounds(60) and are not very accurate since there is a high variability in laboratory measurements. On the other hand, TcB measurements may be used not only as a screening device but also as a reliable substitute for clinical laboratory-based serum bilirubin measurements which is in line with the recent National Academy of Clinical Biochemistry laboratory medicine practice guidelines, which concluded that the TcB meters currently available for clinical use in the US (BiliChek and JM-103) provide results comparable to laboratory TSB (44,61). Above all, when comparing TcB and TSB measurements, it is also important to remember that the 2 methods of measurement may be evaluating different physiologic entities. A study conducted by Rubaltelli et al (34) suggested that TcB methods measure the amount of bilirubin that has moved from the serum into the tissue, possibly mimicking the movement of bilirubin across the blood-brain barrier and into brain tissue, whereas laboratory-based methods measure only bilirubin that is circulating in the blood. Thus, TcB may actually offer additional information not by TSB measurements, although this hypothesis remains to be proven. Another study conducted by hammati et al(18) to see the correlation between TSB and TcB on bilicheck revealed a statistically significant correlation between the Bilicheck ${ }^{\circledR}$ readings and TSB levels. The correlation coefficient in the study conducted by hammati et al $(\mathrm{r}=0.969)$ was comparable to those obtained by Rubaltelli et al $(\mathrm{r}=0.89)(34)$,Ebbsen et al $(\mathrm{r}=0.88)(57)$, Roberston et al(62) $(\mathrm{r}=0.937)$, and Janjindamai et al $(63)$ $(\mathrm{r}=0.950)$, thus Bilicheck ${ }^{\circledR}$ readings can, be employed as an alternative to TSB measurements in the range within which the Bilicheck ${ }^{\circledR}$ showed a numeric value (18). Sajjadan et al(64) conducted a study in Iran and concluded that although TcB measurement may underestimate TSB but there is significant correlation between TSB and TcB in healthy preterm infants $(r=0.56, \mathrm{P}<0.001)$ and ill preterm neonates $(\mathrm{r}=0.82, \mathrm{P}<0.001)$. This method can be used for determination of bilirbin levels in preterm neonates and reduces the number of blood sampling.

\section{Quality control for tcb}

Any measurement, TSB or TcB, has potential for error. It is important that the result from a TcB device be reproducible. As with any test that is performed at the point of care, continuing assessment of the competency of the personnel using the device is extremely important. Clearly, this is a major issue not only with $\mathrm{TcB}$ meters but with point-of-care testing in general. Point of care testing refers to any test performed outside of laboratory by clinical personnel and close to the site of patient care. Based on a summary of multiple reports 
during the last twenty years, we realize that devices which provide a noninvasive transcutaneous bilirubin $(\mathrm{TcB})$ measurement have proven to be very useful as screening tools and provide a valid estimate of the total serum bilirubin level (TSB). Published data suggest that these devices provide measurements within 30-50 micromol/L of the TSB levels and can replace laboratory measurement particularly when TSB levels are less than $260 \mathrm{micromol} / \mathrm{L}$. At the present time, in the literature, evidence is insufficient to abandon neonatal serum bilirubin testing and replace it with TcB. However, we have evidence that $\mathrm{TcB}$ can help avoiding potential errors associated with even visual assessment of jaundice and may be useful as screening device to detect significant jaundice and decrease a large number of unnecessary skin punctures.

\section{Limitations of transcutaneous bilirubinometry}

The use of transcutaneous bilirubinometry is associated with limitations including decreasing accuracy at higher bilirubin levels (58). They permit rapid measurements but do not provide fractionation information(65). Although TcB measurements have been shown to correlate well with TSB, TcB can be affected by a variety of factors, such as phototherapy and exposure to sunlight (66-68). The algorithms that transform the TcB measurements into a bilirubin concentration use estimates of hemoglobin concentrations, which decrease approximately $10 \%$ in the first week of life, along with dermal thickness and the melanin content of the skin, both of which are known to impact TcB measurements $(69,70)$. This has led most facilities to limit the use of TcB to infants $<10$ days old. Care must also be taken to avoid testing skin that is bruised, has a birthmark, or is covered with hair. Also, the accuracy of Bilicheck has been seen in premature newborns without phototherapy, even in newborns on mechanical ventilation(71). We agree that TcB is reasonable, if available, in jaundiced newborns of any age, as the discomfort, time, and cost involved are trivial once the instrument is available.

\section{Conclusion}

It can be concluded that the implementation of Universal bilirubin screening definitely lowers the incidence of hyperbilirubinemia but is also associated with increasing use of phototherapy. Also the use of transcutaneous bilirubinometer is non-invasive, painless and bloodless method of screening and is accepted in term and near-term neonates but its value still needs to be established in preterm neonates. Since the validity of transcutaneous bilirubinometry is acceptable till $15 \mathrm{mg} / \mathrm{dl}$, it cannot be used for making decisions about exchange transfusion and also phototherapy.

\section{References}

[1]. Cabra MA, Whitfield JM. The challenge of preventing neonatal bilirubin encephalopathy: a new nursing protocol in the well newborn nursery. Proceedings (Bayl Univ Med Cent) 2005; 18: 217-219.

[2]. $\quad$ Cashore WJ. Neonatal hyperbilirubinemia. N Y State Med. 1991; 91: 476-477.

[3]. Davidson LT, Merritt KK, Weech AA. Hyperbilirubinemia in the newborn. Am J Dis Child. 1941; 61 :958-980.

[4]. Gartner LM. Management of jaundice in the well baby. Pediatrics. 1992; 89:826-828.

[5]. Gourley GR. Bilirubin metabolism and kernicterus. Adv Pediatr. 1997; 44: 173-229.

[6]. Bhutani VK, Johnson L, Sivieri EM. Predictive ability of a predischarge hour- specific bilirubin for subsequent significant hyperbilirubinemia in healthy term and near-term newborns. Pediatrics. 1999; 103: 6-14.

[7]. Harris MC, Bernbaum JC, Polin JR et al. Developmental follow-up of breastfed term and near-term infants with marked hyperbilirubinemia.

[8]. Newman TB, Maisels MJ. Less aggressive treatment of neonatal jaundice and reports of kernicterus : lessons about practice guidelines. Pediatrics 2000; 105: 242-5.

[9]. Dennery PA, Seidman DS, Stevenson DK. Neonatal Hyperbilirubinemia. N Engl J Med 2001; 344: 581-90.

[10]. Brooks JC, Fisher-Owens SA, Wu YW, Strauss DJ, Newman TB. Evidence suggests there was not a "resurgence" of kernicterus in the 1990s. Pediatrics. In press.

[11]. Sgro M. Kernicterus, January 2007 to December, 2008. CPSP Canadian Paediatroc Surveillance Program. Ottawa, Ontario, Canada: Public Health Agency of Canada; 2009: 41-43.

[12]. Sgro M, Campbell D, Shah V. Incidence and causes of severe neonatal hyperbilirubinemia in Canada. CMAJ. 2006; 175:587-590.

[13]. Manning D, Todd P, Maxwell M, Platt M. Prospective surveillance study of severe hyperbilirubinaemia in the newborn in the UK and Ireland. Arch Dis Child Fetal Neonatal Ed. 2007; 92: 342-346.

[14]. Bjerre JV, Petersen JR, Ebbesen F. Surveillance of extreme hyperbilirubinaemia in Denmark. A method to identify the newborn infants. Acta Paediatr. 2008; 97: 1030-1034.

[15]. Bjerre JV, Ebbesen F. Incidence of kernicterus in newborn infants in Denmark [in Danish]. Ugeskr Laeger. 2006; 168: 686-691.

[16]. Burke BL, Robbins JM, Bird TM, Hobbs CA, Nesmith C, Tilford JM. Trends in hospitalizations for neonatal jaundice and kernicterus in the United States, 1988-2005. Pediatrics. Feb 2009; 123(2): 524- 532.

[17]. Kaplan M, Hammerman C. Understanding and preventing severe neonatal hyperbilirubinemia; is bilirubin neurotoxicity really a concern in the developed world?. Clin Perinatol 2004;31:555-575.

[18]. Hemmati F, Kiyani Rad NA. The value of bilicheck as a screening tool for neonatal jaundice in the South of Iran. Iran J Med Sci. 2013 Jun; 38(2): 122-8.

[19]. Ip S, Chung M, Kulig J, O’Brien, Sege R, Glicken S, Maisels MJ, Lau J; An Evidence- based Reveiw of Important Issues Concerning Neonatal Hyperbilirubinemia. American Academy of Pediatrics.Subcommittee on Hyperbilirubinemia. Pediatrics 2004 Jul; 114(1):e 130-53.

[20]. Jackson JC(1997). Adverse events associated with exchange transfusion in healthy and ill newborns. Pediatrics 99: E7. 
[21]. Patra K, Storfer-Isser A, Siner B, Moore J, Hack M(2004). Adverse events associated with neonatal exchange transfusion in the 1990s. J Pediatr 144: 626-631.

[22]. Keenan WJ, Novak KK, Sutherland JM, Bryla DA, Fetterly KL (1985). Morbidity and mortality associated with exchange transfusion. Pediatrics 75: 417.

[23]. Aspberg S, Dahlquist G, Kahan T, Kallen B. Confirmed association between neonatal phototherapy or neonatal icterus and risk of childhood asthma. Pediatr Allergy Immunol. 2010; 21(4 Pt 2): e733-e739.

[24]. Aspberg S, Dahlquist G, Kahan T, Kallen B. Is neonatal phototherapy associated with an increased risk for hospitalized childhood bronchial asthma? Pediatr Allergy Immunol. 2007; 18: 313-319.

[25]. Maisels MJ, McDonagh AF. Phototherapy for neonatal jaundice. N Engl J Med. 2008; 358: 920-928.

[26]. Dahlquist G, Kallen B. Indications that phototherapy is a risk factor for insulin-dependent diabetes. Diabetes Care. 2003; 26:247248.

[27]. Moyer VA, Ahn C, Sneed S. Accuracy of clinical judgement in neonatal jaundice. Arch Pediatr Adolesc Med. 2000; 154(4): 391 394.

[28]. Keren R, Luan X, Friedman S, Saddlemire S, Cnaan A, Bhutani VK. A comparison of alternative risk- assessment strategies for predicting significant neonatal hyperbilirubinemia in term and near-term infants. Pediatrics. 2008; $121: \mathrm{e} 170$-e179.

[29]. Moyer VA, Ahn C, Sneed S. Accuracy of clinical judgement in neonatal jaundice. Arch Pediatr Adolesc Med. 2000;154:391-394.

[30]. American Academy of Pediatrics, Subcommittee on Hyperbilirubinemia. Management of hyperbilirubinemia in the newborn infant 35 or more weeks of gestation. Pediatrics.2004; 114(1):297-316.

[31]. KJ Barrington, K Sankaran. Canadian Paediatric Society, Fetus and Newborn Committee Guidelines for detection, management and prevention of hyperbilirubinemia in term and late preterm newborn infants (35 or more weeks' gestation) Paediatr Child Health. 2007; 12(Suppl B): 1B-12B.

[32]. AAP Subcommittee on Neonatal Hyperbilirubinemia, Neonatal jaundice and kernicterus. Pediatrics 2001;108(3):763-765.

[33]. Eggert LD, Wiedmeier SE, Wilson J, Christensen RD. The effect of instituting a prehospital-discharge newborn bilirubin screening program in an 18-hospital health system. Pediatrics . 2006;117(5).

[34]. Rubaltelli FF, Gourley GR, Loskamp N, Modi N, Roth-Kleiner M, Sender A, et al. Transcutaneous bilirubin measurement: A multicenter evaluation of a new device. Pediatrics. 2001; 107: 1264-71.

[35]. Karoly L, Pohlandt F, Muche R, Mihatsch WA. Transcutaneous bilirubinometry in very low birth weight infants. Acta Paediatr. 2004; 93: 941-4.

[36]. Maisels MJ. Transcutaneous bilirubinometry. Neo-Reveiws 2006; 7: e217-25.

[37]. Bosschaart N, Kok J, Newsum A, Ouweneel D, Mentink R, van Leeuwen T, et al. Limitations and opportunities of transcutaneous bilirubin measurements. Pediatrics 2012; 129:680-94.

[38]. Samanta S, Tan M, Kissack C, Nayak S, Chittick R, Yoxall CW. The value of Bilicheck as a screening tool for neonatal jaundice in term and near-term babies. Acta Paediatr.2004;93:1486-90. Doi.: 10.1111/j. 1651-2227.2004.tb02634.x.

[39]. Ho EY, Lee SY, Chow CB, Chung JW. BiliCheck transcutaneous bilirubinometer: a screening tool for neonatal jaundice in the Chinese population. Hong Kong Med J. 2006; 12: 99-102.

[40]. Yasuda S, Itoh S, Isobe K. New transcutaneous jaundice device with two optical paths. J Perinat Med. 2003; 13: 81-88.

[41]. De Luca D, Zecca E, Corsello M, Tiberi E, Semeraro C, Romagnoli C. Attempt to improve transcutaneous bilirubinometry: a double-blind study of Medick Bilimed versus Respironics Bilicheck. Arch Dis Child Fetal Neonatal Ed 2008;93(2):F135-F139.

[42]. Raimondi F, Lama S, Landolfo F, Sellitto M, Borrelli AC, Maffucci R, Milite P, Capasso L. Measuring transcutaneous bilrubin: a comparative analysis of three devices on a multiracial population. BMC Pediatrics. 2012 Jun 14;12:70.

[43]. Nichols JH, Christenson RH, Clarke W, Gronowski A, Hammett-Stabler CA, Jacobs E, et al. Executive summary. The National Academy of Clinical Biochemistry Laboratory Medicine Practice Guideline: evidence-based practice for point-of-care testing. Clin Chim Acta 2007;379:14-28.

[44]. Kazmierczak S, Bhutani V, Gourley G, Kerr S, Lo S, Robertson A, Sena SF. Transcutaneous bilirubin testing. In: Laboratory medicine practice guideline: evidence-based practice for point-of-care testing. AACC Press 2007;5-12.

[45]. Randeberg LL, Roll EB, Nilsen LTN, Christensen T, Svaasand LO. In vivo spectroscopy of jaundiced newborn skin reveals more than a bilirubin index. Acta Paediatr 2005;94:65-71.

[46]. Maisels MJ, Ostrea EM, Jr, Touch S, Clune SE, Cepeda E, Kring E, et al. Evaluation of a new transcutaneous bilirubinometer. Pediatrics 2004;113:1628-1635.

[47]. Poland RL, Hartenberger C, Mc Henry H, Hsi A. Comparison of skin sites for estimating serum total bilirubin in in-patients and out-patients: Chest is superior to brow. J Perinatol 2004 Sep;24(9):541-3.

[48]. El-Beshbishi SN, Shattuck KE, Mohammad AA, Petersen JR. Hyperbilirubinemia and Transcutaneous bilirubinometry. Clin Chem 2009 Jul;55(7):1280-7.

[49]. Yaser A, Tooke L, Rhoda N. Interscapular site for transcutaneous bilirubin measurement in preterm infants: a better and safer screening site. Clin Chem 2009 Jul;55(7):1280-7.

[50]. Ferreira D, Oliveira A, Freitas A. Applying data mining techniques to improve diagnosis in neonatal jaundice. BMC Med Inform Decis Mak. 2012 Dec 7;12:143.

[51]. Petersen JR, Okorodudu AO, Mohammad AA, Fernando A, Shattuck KE. Association of transcutaneous bilirubin testing in hospital with decreased readmission rate for hyperbilirubinemia. Clin Chem 2005;51(3):540-544.

[52]. Maisels MJ, Kring E. Transcutaneous bilirubinometry decreases the need for serum bilirubin measurements and saves money. Pediatrics.1997;99(4):599-601.

[53]. Mishra S, Chawla D, Agarwal R, Deorari AK, Paul VK, Bhutani VK. Transcutaneous bilirubinometry reduces the need for blood sampling in neonates with visible jaundice. Acta Paediatr. 2009;98(12):1916-1919.

[54]. Briscoe L, Clark S, Yoxall CW. Can transcutaneous bilirubinometry reduce the need for blood tests in jaundiced full term babies? Arch Dis Child Fetal Neonatal Ed. 2002;86(3):F190-F192.

[55]. Dai J, Parry DM, Krahn J. Transcutaneous bilirubinometry: its role in the assessment of neonatal jaundice. Clin Biochem. 1997;30(1):1-9.

[56]. Lillien D, Harris VJ, Ramamurthy RS, Pildes RS. Neonatal osteomyelitis of the calcaneous : complication of heel puncture. J Pediatr.1976;88(3):478-480.

[57]. Ebbesen F, Rasmussen LM, Wimberley PD. A new transcutaneous bilirubinometer, BiliCheck, used in the neonatal intensive care unit and maternity ward. Acta Paediatr.2002;91:203-11.

[58]. O'Connor MC, Lease MA, Whalen BL. How to use: transcutaneous bilirubinometry. Arch Dis Child Educ Pract Ed. 2013 Aug;98(4):154-9.

[59]. Lo S, Doumas BT, Ashwood E. Performance of bilirubin determinations in US laboratories-revisited. Clin Chem 2004; 50:190-194. 
[60]. Kazmierczak SC, Robertson AF, Briley KP. Comparison of hemolysis in blood samples collected using an automatic incision device and a manual lance. Arch Pediatr Adolesc Med 2002;156:1072-1074.

[61]. Nichols JH, Christenson RH, Clarke W, Gronowski A, Hammett-Stabler CA, Jacobs E, et al. Executive summary. The National Academy of Clinical Biochemistry Laboratory Medicine Practice Gudeline: evidence-based practice for point-of-care testing. Clin Chim Acta 2007;379:14-28.

[62]. Robertson A, Kazmierczak S, Vos P. Improved transcutaneous bilirubinometry: comparison of SpectR(X) Bilicheck and Minolta Jaundice Meter JM-102 for estimating total serum bilirubin in a normal newborn population. J Perinatol. 2002;22:12-4.

[63]. Janjindamai W, Tansantiwong T. Accuracy of transcutaneous bilirubinometer estimates using Bilicheck in Thai neonates. J Med Assoc Thai. 2005;88:187-90.

[64]. Sajjadian N, Shajari H, Saalehi Z, Esphahani F, Alizadeh Taheri P. Transcutaneous bilirubin measurement in preterm neonates. Acta Med Iran. 2012 Nov;50(11):765-70.

[65]. Yamamoto LG, Killeen J, French GM. Transcutaneous bilirubin measurement methods in neonates and its utility for emergency department use. Pediatr Emerg Care. 2012 Apr;28(4):380-4.

[66]. Tan KL, Dong F. Transcutaneous bilirubinometry during and after phototherapy. Acta Paediatr 2003;92:327-331.

[67]. Knupfer M, Pulzer F, Braun L, Heilmann A, Robel- Tillig E, Vogtmann C. Transcutaneous bilirubinometry in preterm infants. Acta paediatr 2001;90;899-903.

[68]. Ozkan H, Oren H, Duman N, Duman M. Dermal bilirubin kinetics during phototherapy in term neonates. Acta Paediatr 2003;92:577-581.

[69]. Yamanouchi I, Yamauchi Y. Transcutaneous bilirubinometry: effect of postnatal age. Acta Paediatr Jpn 1991;33:663-667.

[70]. Onks D, Silverman L, Robertson A. Effect of melanin, oxyhemoglobin, and bilirubin on transcutaneous bilirubinometry. Acta Paediatr 1993;82;19-21.

[71]. Badiee Z, Mohammadizadeh M, Shamee M. Diagnostic Usefulness of Transcutaneous Bilirubinometry in Very Preterm Newborns. Int J Prev Med. Apr 2012;3(4):262-265. 